\section{Aging in Place}

Gail Low ${ }^{1}$, Sofia von Humboldt ${ }^{2}$, Mary Kalfoss ${ }^{3}$, Donna M. Wilson ${ }^{1}$ and Isabel Leal ${ }^{2}$

${ }^{1}$ Faculty of Nursing, University of Alberta, Edmonton, AB, Canada

${ }^{2}$ William James Center for Research, ISPA Instituto Universitário, Lisbon, Portugal

${ }^{3}$ Faculty of Health Sciences, VID Specialized University, Oslo, Norway

\section{Synonyms}

Age-friendly environments; Attachment to place; Insideness; Intrinsic capacity; Staying put

\section{Definition}

To age in place means to grow old in one's own home rather than in an institution such as a nursing home or assisted living facility (Abramsson and Andersson 2016; Schorr and Khalaila 2018). Ideally, this is also in a long-term family home (Barrett et al. 2012), in their similar neighborhoods and broader communities (Kim et al. 2017). Aging in place is also about being able to live independently (Schorr and Khalaila 2018). More specifically, aging in place is the ability of older people to live in their own homes and communities safely, autonomously, and comfortably, regardless of age, income, or functional limitations (World Health Organization 2017). To age in place is therefore to "stay put" in one's home and community (Wiles et al. 2012, 2017). As Thang and Hong (2015) point out, aging in place is growing old in the home, community, and environment that one is familiar with, with minimal change or disruption to one's life and thus also one's activities. Broadly speaking, to age in place is to continue to live in the same "place" as always (Lofqvist et al. 2013).

\section{Overview}

\section{Attachment to Place}

There has been a significant amount of crosssectional research done on the attachment to place, particularly in relation to one's own home. Home is a place where familiar routines and habits are enacted (Bostrom et al. 2017; Coleman et al. 2016; Granbom et al. 2014; Lindley and Wallace 2015; Roy et al. 2018). Personal possessions in public display (Cristoforetti et al. 2011; Lindley and Wallace 2015; Shen and Perry 2016) and familiar smells and sounds (Board and McCormack 2018) bring a sense of comfort, control, and security. A home is where memories are built and shared that forge connections between past and present selves (Degnen 2016; Stones and Gullifer 2016). A home is thus an autobiographical symbol of who we were and who we have become (Rowles 1993). Private home spaces provide opportunities for quiet reflection on one's 
past life experiences (Cristoforetti et al. 2011). A home is a showcase (Cristoforetti et al. 2011) and an extension of one's self (Grenier et al. 2016; Peace et al. 2011), enhancing psychological wellbeing and autonomy (Board and McCormack 2018), and perceived health (Barry et al. 2018) in older age.

\section{Physical and Social Insideness}

Attachment to place grows with aging (Abramsson and Andersson 2016; Granbom et al. 2014; Cramm et al. 2018; Wiles et al. 2017). Maintaining a relationship with one's neighborhood through living in or close to it while also having easy access to everyday services is a resource for aging in place (Roy et al. 2018). Proximity and access are thus part of what makes a community a good place to live in older age (van der Pas 2015). Familiarity with and access to physical surroundings enhances feelings of connectedness to place and reduces loneliness (Schorr and Khalaila 2018). Changes to familiar neighborhoods are associated with depression and anxiety (Smith et al. 2018). Neighborhoods are physical spaces to develop meaningful connections through mundane everyday social practices (Degnen 2016). Familiar local social contacts help older people feel connected to their neighborhood (Lager et al. 2016; Wiles et al. 2012, 2017). Everyday social practices provide a sense of neighborhood identity (Ye and Chen 2014) and become an extension of the self (Severinsen et al. 2016; Wiles et al. 2012). Being part of the social fabric of local life affords older people social insideness or a sense of social affinity (Rowles 1993). Neighborhoods and communities are therefore part-and-parcel of older people's homes (Lager et al. 2016).

Aging in place is also about maintaining and sustaining a home, even when one's physical functioning declines (Barry et al. 2018). Older people often reconfigure their home to carry on necessary activities of daily living (HillcoatNalletamby and Ogg 2014). These continuing routine activities foster a sense of self-in-place (Peace et al. 2011), enhance psychological wellbeing (Freedman et al. 2017), and provide a sense of security and control (Bostrom et al. 2017), as well as continuity (Lindley and Wallace 2015), and comfort (Peace et al. 2011). Older people say their ability to carry on these familiar activities demonstrates their ability to live independently (Granbom et al. 2014; Lofqvist et al. 2013; Roy et al. 2018) and keeps normal daily life on track (Barrett et al. 2012). Doing for oneself enhances the sense of control and autonomy (Barry et al. 2018; Dupuis-Blanchard et al. 2015; Stones and Gullifer 2016) and psychological well-being (Board and McCormack 2018). A sense of physical insideness comes from the repetitive use of spaces in the home for carrying out familiar activities (Rowles 1993).

\section{Key Research Findings}

\section{Intrinsic Capacity}

It is abundantly clear that older people value aging in place. Aging in place is about expressing and retaining a sense of identity, social relationships, and autonomy or independence and choice (World Health Organization 2017). At the heart of aging in place then is the intrinsic need for residential normalcy, for not surrendering the life and home that one has carefully and thoughtfully constructed over time (Golant 2011). Older people have the basic need and right to have a life (World Health Organization 2017, p. 18) and to exercise their intrinsic capacity to do so (World Health Organization 2015). Intrinsic capacity refers to older people's combined physical, mental, and social capabilities (World Health Organization 2017). An interesting application of intrinsic capacity is Peace et al.'s (2011) notion of "option recognition": where older people are said to strategically modify and remodify their behavior and living environments to maintain self-identity. The physical reconfiguring of the home comprise options that older people have recognized and exercised. Downsizing to meet physical limitations has helped some physically redesign their lives; age-friendly homes make the very idea of spending more time at home palatable, including a place to display pictures of foregone but cherished possessions (Lindley and Wallace 2015). Others selectively engage in or 
give up cherished activities (Granbom et al. 2014).

Older people socially reconfigure their homes as well. Most often, older people reach out to available supports from existing social networks for emotional and practical reasons (Cristoforetti et al. 2011; Greenfield 2016; Peace et al. 2011; Roy et al. 2018; Severinsen et al. 2016; Shen and Perry 2016; Wiles et al. 2012; Dupuis-Blanchard et al. 2015; Coleman et al. 2016). Neighbors check in and give advice (Greenfield 2016). Some have friends and neighbors help with physically demanding self-care tasks (Thang and Hong 2015). Indeed, family and long-term friends often help with household chores (Lofqvist et al. 2013). Accepting help from others can be a way of normalizing one's current living situation (Granbom et al. 2014; Peace et al. 2011). Moreover, some older people speak of volunteering while they are still able to be out and about to expand their instrumental and emotional informal support networks in preparation for future functional limitations (Shen and Perry 2016). For very-old people living with limited mobility, watching and listening to the comings and goings of people in the neighborhood through a window helps them retain some semblance of a normal life (Lager et al. 2016). Even a restricted or more isolated life is preferred to being a burden to others and letting go of a normal life (Barry et al. 2018; Peace et al. 2011).

\section{Age-Friendly Environments}

Age-friendly environments or AFEs are designs said to complement older people's intrinsic capacity to carry on doing what is important to them (World Health Organization 2015, 2017). An exemplar of this is the Community Aging in Place, Advancing Better Living for Elders program (Szanton et al. 2015) which was designed for urban dwellers living with multiple functional and income limitations. Home modifications and repairs with Occupational Therapists and handymen and ongoing assessments by registered nurses help participants carry on routine activities. Another innovative example is NORCs or Naturally Occurring Retirement Community Supportive Service Programs (Greenfield and Mauldin 2017). NORCs are community-based programs that consist of older people, local service providers, and housing managers. NORCs offer accessible group recreational and health promotion activities, and volunteer work, and link older people to home repair and transport services. These key features of AFEs potentially help older people carry on or extend social networks (World Health Organization 2015). NORC programs have been found to enhance older people's sense of community and friendships (Greenfield and Mauldin 2017).

AFEs often make use of "assistive" technologies, ones suited to the needs and wants of older people who wish to remain at home (World Health Organization 2015). Downsizers have used technology to create visible images of cherished possessions or to carry on meaningful music hobbies that bring a sense of continuity to daily life (Lindley and Wallace 2015). Telehealth services such as lifelines for emergency response support appear to curtail the continuity of desirable and thus important activities outside the home (Aceros et al. 2016). Yet, very little is known however about how home-based technology affects people's desires and expectations to age in place.

\section{Future Directions of Research}

The rich narratives of older people tell us that they are anything but passive in their relationship with their environment (World Health Organization 2015, p. 35). COVID-19 was deemed a 2020 public health emergency across the globe (World Health Organization 2020a). Social distancing measures are used to help contain the outbreak (World Health Organization 2020b). Social practices are primarily confined now to older people's homes. Qualitative studies are needed about whether and how spending more time at home enhanced older people's sense of attachment to home during COVID-19. Traumatic events can be more daunting with a loss of safety within everyday territories (Hobfoll et al. 2007). Older people $60+$ years of age are at a greater risk for lifethreatening COVID-19 complications (United Nations 2020). During COVID-19, the home became a refuge for older people to 'safely' age 
in place. Older people began living predominantly virtual lives with COVID-19.

Further exploration of how older people retained their ability to have a life during the COVID-19 pandemic, such as through option recognition and everyday life designs, is warranted. Significant and irreversible changes in functioning could arise from older people feeling 'stuck in place' (Lehning et al. 2015; Lindley and Wallace 2015). Longitudinal studies will help us better understand how changes shape older people's desires and expectations to age in place. We also need to identify age-friendly features of built and social environments that older people believe make a home, neighborhood, and community the place to still have a life.

Assistive technology, such as the Internet, was likely a key feature in older people's lives during COVID-19. Research is needed on how older people used assistive technology to still have a life at home. For example, do older people conceive of assistive technology as an option to help them socially reconfigure their homes? How do older people use assistive technology to stay meaningfully connected to social contacts in their neighborhoods and communities? How do these intrinsic abilities bring a sense of normalcy or continuity in everyday life during COVID-19?

In a similar vein, how do older people perceive and respond to changes in familiar built and social environments? Very little is known about how changes to familiar places over time shape older people's desires and expectations to age in place (World Health Organization 2015). Prior to COVID-19, threats to physical safety limited some older people's expectations to age in place (Lehning et al. 2015). Frail-older people reported needing safe outdoor spaces in their neighborhoods (Cramm et al. 2018). As COVID-19 social distancing restrictions wan, research must better understand what safe everyday designs outside the home look like. It is also not known whether and how innovative resource-rich programs such as the CAPABLE and NORC programs have affected older people's desires and expectations to age in place. In conclusion, future research with COVID-19 must explore interactions between older people's intrinsic abilities and living environments and their desires and expectations to age in place.

\section{Cross-References}

\author{
- Age-Friendly Cities and Communities \\ - Aging and Housing: Home Adaptations \\ - Aging and Housing: Independent Living \\ - Assistive Technology Device Predisposition \\ Assessment \\ - COVID-19 and Healthy Aging \\ - Matching Person and Technology Model \\ $\checkmark$ Person-Environment Fit
}

\section{References}

Abramsson M, Andersson E (2016) Changing preferences with ageing - housing choices and housing plans of older people. Hous Theory Soc 33(2):217-214. https:// doi.org/10.1080/140336096.2015.1104385

Aceros JC et al (2016) Aging at home with telecare in Spain: a discourse analysis. Cien Saude Colet 21(8):2413-2421. https://doi.org/10.1590/1413-81232015218.13472015

Barrett $P$ et al (2012) Social inclusion through ageing-inplace with care? Ageing Soc 32(3):361-378. https:// doi.org/10.1017/S0144686X11000341

Barry A et al (2018) The meaning of home for ageing women living alone: an evolutionary concept analysis. Health Soc Care Community 26:337-344. https://doi. org/10.1111/hsc. 12470

Board M, McCormack B (2018) Exploring the meaning of home and its implications for the care of older people. J Clin Nurs 27(15-16):3070-3080. https://doi.org/ 10.1111/jocn. 14495

Bostrom $\mathrm{M}$ et al (2017) How older people perceive and experience sense of security when moving into and living in a nursing home: a case study. Eur J Soc Work 20(5):697-710. https://doi.org/10.1080/13691457. 2016.1255877

Coleman T et al (2016) Older adults' experiences of home maintenance issues and opportunities to maintain ageing in place. Hous Stud 31(8):964-983. https://doi.org/ 10.1080/02673037.2016.1164834

Cramm JM et al (2018) The creation of age-friendly environments is especially important to frail older people. Ageing Soc 38(4):700-720. https://doi.org/10.1017/ S0144686X16001240

Cristoforetti A et al (2011) Home sweet home: the emotional construction of places. J Aging Stud 25:225-232. https://doi.org/10.1016/j.jaging.2011.03.006

Degnen C (2016) Socialising place attachment: place, social memory and embodied affordances. Ageing 
Soc 36(8):1645-1667. https://doi.org/10.1017/S0144 $686 \times 15000653$

Dupuis-Blanchard S et al (2015) Strategies for aging in place: the experience of language-minority seniors with loss of independence. Global Qual Nurs Res 2:1-9. https://doi.org/10.1177/2333393614565187

Freedman VA et al (2017) Successful aging through successful accommodation with assistive devices. J Gerontol B Psychol Sci Soc Sci 72(2):300-309. https://doi.org/10.1093/geronb/gbw102

Golant SM (2011) The quest for residential normalcy by older adults: relocation but one pathway. J Aging Stud 25(3):193-205. https://doi.org/10.1016/j.jaging.2011. 03.003

Granbom M et al (2014) Residential normalcy and environmental experiences of very old people: changes in residential reasoning over time. J Aging Stud 29:9-19. https://doi.org/10.1016/j.jaging.2013.12.005

Greenfield EA (2016) Support from neighbors and aging in place: can NORC programs make a difference? Gerontologist 56(4):651-659. https://doi.org/10.1093/geront/ gnu 162

Greenfield EA, Mauldin R (2017) Participation in community activities through Naturally Occurring Retirement Community (NORC) Supportive Service Programs. Ageing Soc 37(1):1987-2011. https://doi.org/10.1017/ S0144686x16000702

Grenier A et al (2016) Homelessness and aging: the contradictory ordering of 'house' and 'home'. J Aging Stud 39:73-80. https://doi.org/10.1016/j.jaging.2016.11.002

Hillcoat-Nalletamby S, Ogg J (2014) Moving beyond 'ageing in place': older people's dislikes about their home and neighbourhood environments as a motive for wishing to move. Ageing Soc 34(10):1771-1796. https:// doi.org/10.1017/S0144686X13000482

Hobfoll SE et al (2007) Five essential elements of immediate and mid-term mass trauma intervention: Empirical evidence. Psych, 70(4):283-315. https://doi.org/ 10.1521/psyc.2007.70.4.283

Kim B et al (2017) Community-based services and depression from person-environment fit perspective: focusing on functional impairments and living alone. J Gerontol Soc Work 60(4):270-285. https://doi.org/10.1080/ 01634372.2017 .1310166

Lager D et al (2016) Rhythms, ageing and neighbourhoods. Environ Plan A 48(8):1565-1580. https://doi.org/ $10.1177 / 0308518 X 16643962$

Lehning AJ et al (2015) Do age-friendly characteristics influence the expectations to age in place? A comparison of low-income and higher income Detroit elders. J Appl Gerontol 34(2):158-180. https://doi.org/10.1177/ 0733464813483210

Lindley S, Wallace J (2015) Placing in age: transitioning to a new home in later life. ACM Trans Comput Hum Interact 22(4):article 20. https://doi.org/10.1145/ 2755562

Lofqvist C et al (2013) Voices on relocation and aging in place in very old age: a complex and ambivalent matter.
Gerontologist 53(6):919-927. https://doi.org/10.1093/ geront/gnt034

Peace S et al (2011) 'Option recognition' in later life: variations in ageing in place. Ageing Soc 31(5):734-757. https://doi.org/10.1017/S0144686X10001157

Rowles GD (1993) Evolving images of place aging and 'Aging in Place'. Generations 17(2):65-71

Roy N et al (2018) Choosing between staying at home or moving: a systematic review of factors influencing housing decisions among frail older adults. PLoS ONE. https://doi.org/10.1371/journal.pone.0189266

Schorr AV, Khalaila R (2018) Aging in place and quality of life among the elderly in Europe: a moderated mediation model. Arch Gerontol Geriatr 77(1):196-204. https://doi.org/10.1016/j.archger.2018.04.009

Severinsen C et al (2016) Ageing in unsuitable places. Hous Stud 31(6):714-728. https://doi.org/10.1080/ 02673037.2015 .1122175

Shen HW, Perry T (2016) Interdependence between the social and material convoy: links between volunteering, with World Health Organization, and housing transitions. Soc Work Res 40(2):71-82. https://doi.org/10.1093/swr/svw002

Smith RJ et al (2018) Aging in place in gentrifying neighborhoods: Implications for physical and mental health. Gerontologist 58(1):26-35. https://doi.org/10.1093/ geront/gnx 105

Stones D, Gullifer J (2016) 'At home it's just so much easier to be yourself': older adults' perceptions of ageing in place. Ageing Soc 36(3):449-481. https://doi. org/10.1017/S0144686X14001214

Szanton SL et al (2015) Preliminary data from CAPABLE, a patient directed, team-based intervention to improve physical function and decrease nursing home utilization: the first 100 completers of a CMS innovations project. J Amer Geriatr Soc 63(2):371-374

Thang LL, Hong SI (2015) Ageing-in-place in studio apartments in Singapore: maintaining independence in community living. Asia Pac J Soc Work 25(4):250-263. https://doi.org/10.1080/02185385.2015.1120414

United Nations (2020). United Nations policy brief: COVID-19 and the need for action on mental health. https://www.un.org/sites/un2.un.org/files/un_policy_ brief-covid_and_mental_health_final.pdf

van der Pas S et al (2015) Features of home and neighbourhood and the liveability of older South Africans. Eur J Ageing 12(3):215-227. https://doi.org/ 10.1007/s10433-105-0343-2

Wiles JL et al (2012) The meaning of "aging in place" to older people. Gerontologist 52(3):357-366. https://doi. org/10.1093/geront/gnr098

Wiles JL et al (2017) Attachment to place in advanced age: a study of the LiLACS NZ cohort. Soc Sci Med 185:27-37. https://doi.org/10.1016/j.socscimed.2017.05.006

World Health Organization (2015) World report on ageing and health. http://www.WorldHealthOrganization.int/ ageing/events/world-report-2015-launch/en/. Accessed 15 Nov 2018 
World Health Organization (2017) Global strategy and action plan on ageing and health. https://www.WorldHealthOrga nization.int/ageing/global-strategy/en/. Accessed 15 Nov 2018

World Health Organization (2020a). WHO Director-General's opening remarks at the media briefing on COVID19 - 11 March 2020. https://www.who.int/dg/speeches/ detail/who-director-general-s-opening-remarks-at-themedia-briefing-on-covid-19
World Health Organization (2020b). Coronavirus disease (COVID-19) advice for the public. https://www.who. int/emergencies/diseases/novel-coronavirus-2019/advi ce-for-public

Ye M, Chen, Y (2014) The influence of domestic living arrangement and neighborhood identity on mental health among urban Chinese elders. Aging Ment Health 18(1):40-50. https://doi.org/10.1080/13607863. 2013.837142 